\title{
Influence of Treated Natural Jute Fiber on Flexural Properties of Reinforced Concrete Beams
}

\author{
Bharathi Murugan.R ${ }^{1}$, Ajit Gayke ${ }^{2}$, Natarajan.C ${ }^{3}$, Haridharan.M.K ${ }^{4}$, Murali.G ${ }^{5}$, Parthiban .K ${ }^{6}$ \\ ${ }^{I}$ Department of Civil Engineering, Vaagdevi college of Engineering, Warangal, Telangana, India. \\ ${ }^{2,3}$ Department of Civil Engineering, National Institute of Technology, Tiruchirappalli, India. \\ ${ }^{4}$ Department of Civil engineering, Amrita School of Engineering, Coimbatore, Amrita Vishwa Vidyapeetham, India. \\ ${ }^{5,6}$ School of Civil Engineering, SASTRA To Be Deemed University, Thanjavur, India. \\ *Corresponding author:harai411@gmail.com ${ }^{4}$, rbmmecivil@gmail.com ${ }^{1}$, nataraj@nitt.edu ${ }^{3}$ \\ murali@civil.sastra.edu, ${ }^{5}$ parthiban@civil.sastra.edu ${ }^{6}$
}

\begin{abstract}
India is one of the largest producers of jute, its potential use in many branches of engineering should be developed for the prosperity of the nation. The recent trends in utilizing the natural fibers has increased due to its advantages over synthetic fibers due to low cost, low environment hazard and easy availability. The properties of the fiber is improved by treating the jute fiber with alkali and latex polymer. Since, very few studies been conducted using the treated jute fiber concrete, an experimental work was carried with $0.6 \%$ as optimum percentage of treated jute fibers based on the mechanical properties of concrete. The influence of flexural characteristics of concrete was compared with control beams and beams cast with fibers in whole area and also only in tension zone of beam for M20 and M25 concrete grade. The beams with fibers of whole area had better strength, stiffness characteristic than the control beam and the beam with fibers in tension zone only. The initial cracking load was increased by $12.92 \%$ and $11.23 \%$ and ultimate load was increased by $6.94 \%$ and $7.20 \%$ for the beams cast with fibers in whole area for M20 and M25 grade of concrete, respectively.
\end{abstract}

Keywords: Jute fiber, alkali, Polymer Latex, flexural strength

\section{Introduction}

Production of a durable and economical natural fiber has become trend and an alternate to synthetic fiber which exploits the environment before and after it production [1-3]. The nation India tops the table worldwide in producing and consuming country and accounts for about $60 \%$ of the world production of jute fibres. [4]. Natural fibers such as sisal, coconut, sugar-cane bagasse, hemp, jute are reported to yield improved mechanical strength of the cement based composites [5-8]. Reviewing the literature, it is understood addition of natural fibers enhances the mechanical properties, post-cracking resistance, high energy absorption most suitable for seismic areas, fatigue strength and also it is economy and using manufacturing of precast light weight walls and roofing [9-13]. In addition to the above advantage it remains difficult to understand its durability aspect of natural fibers and also the disperse of the fibers in the concrete [1418].The present study uses the natural fibers which was treated with optimum dosage of alkali solution at room temperature. Alkali treated jute fibers were again treated with polymer latex to improve its durability and mechanical characteristic of treated jute fiber. [19-22].

\section{Experimental Research}

\section{Raw Materials}

Ordinary Portland cement of 43 grade conforming to BIS 8112 [23]. River sand confirming to Zone II specifications [24] was

used as fine aggregates and crushed granite was used as coarse aggregate. Coarse aggregate of two sizes: $20 \mathrm{~mm}$ and $12.5 \mathrm{~mm}$, were used in a mix proportion of 50\% each. The properties of the aggregate are shown in Table 1.

Table 1: Properties of Aggregate

\begin{tabular}{|c|c|c|c|}
\hline \multirow{2}{*}{ Content } & \multicolumn{2}{|c|}{ Coarse Aggregate } & \multirow{2}{*}{ Fine Aggregate } \\
\cline { 2 - 3 } & $20 \mathrm{~mm}$ & $12.5 \mathrm{~mm}$ & \\
\hline Density g/cm & 2.65 & 2.643 & 2.59 \\
\hline Fineness modulus & 7.07 & 6.72 & 2.70 \\
\hline Specific Gravity & 2.70 & 2.72 & 2.65 \\
\hline Water Absorption & 0.40 & 0.40 & 0.60 \\
\hline
\end{tabular}

\section{Natural Fibers and Chemical treatment}

Fibers were made out of the jute were considered, these fibers were chemically treated to enhance their durability and tensile strength properties of raw jute. These jute fibers were cut into a length of $50 \mathrm{~mm}$ and then subjected to chemical treatment. The chopped raw fibers were soaked in $0.5 \%$ alkali solution at room temperature. The fibers were kept immersed in the alkali solution for $24 \mathrm{~h}$. Then distilled water was used to remove the excess alkali 
present in the fiber by washing it several times till the $\mathrm{pH}$ in the fiber was 7.0. Then the fibers were dried in controlled manner for room temperature and the by oven drying for $24 \mathrm{~h}$ for each process. Alkali treated jute fibers were dipped into $0.5 \%$ polymer latex (carboxylate styrene-butadiene copolymer based polymer latex) for $24 \mathrm{~h}$ at room temperature condition. Then fibers were dried till the moisture content was driven. Table 2 shows mechanical properties of raw jute fibers and treated jute fibers. There was meager variations in the mechanical properties between the raw and treated jute fibers.

\section{Mix Proportions}

The concrete mix design for M20 and M25 was carried out based on BIS 10262-2009 [25]. The ratio of material were fixed for each grade of concrete and the addition of treated fibers with respect to cement are shown in Table 3.

\section{Experimental Set Up and Test Procedure}

The experiments were conducted in two sets. In first set, the fresh properties and hardened properties of two different concrete grades were studied for three different percentage of fiber content to optimize the fiber content. In the second phase, flexure behavior study was conducted on three types of concrete beams based on the distribution of fibers for each concrete grade. The first one was control beam (CCB), the second one was with the presence of treated jute fiber in full length of concrete beam

(FCB) and the last one was with the presence of half the depth of beams with Jute fibre reinforced concrete (at bottom) (FHCB) and remaining with normal concrete beams. The reinforcement details and experimental set up of reinforced concrete beam are shown in figure $2 \& 3$. The test program consists of 18 beams. The span of all beams was $1500 \mathrm{~mm}$ with a cross section of $100 \times 200 \mathrm{~mm}$. These beams were reinforced with 2 bars of $10 \mathrm{~mm}$ diameter steel bars in tension side and 2 bars of $8 \mathrm{~mm}$ diameter steel bars in compression side with 6 $\varphi \mathrm{mm}$ steel stirrups @ $150 \mathrm{~mm}$ center to center are shown in figure 2 . The beam was tested under a four point loading condition. The load was applied by 30 metric ton power controlled hydraulic jack, the deflection were measured at the mid span, span by three distance by using linear variable differential transducer (LVDT). The reinforcement detailing of beams and experimental set up is shown in figure 1 and 2, respectively.

Table 2: Properties of Jute Fibres

\begin{tabular}{|c|c|c|c|}
\hline S.No. & Property & $\begin{array}{c}\text { Raw Jute } \\
\text { fiber }\end{array}$ & $\begin{array}{c}\text { Treated Jute } \\
\text { Fibers }\end{array}$ \\
\hline 1 & Density $\left(\mathrm{g} / \mathrm{cm}^{3}\right)$ & 1.3 & 1.5 \\
\hline 2 & Elongation $(\%)$ & 1.7 & 1.8 \\
\hline 3 & $\begin{array}{c}\text { Tensile Strength } \\
(\mathrm{MPa})\end{array}$ & $393-473$ & $410-493$ \\
\hline 4 & $\begin{array}{c}\text { Young's Modulus } \\
(\mathrm{GPa})\end{array}$ & $23.5-26.5$ & $21-24$ \\
\hline
\end{tabular}

Table 3: Mix Proportions of Concrete

\begin{tabular}{|c|c|c|c|c|c|c|}
\hline \multirow{2}{*}{$\begin{array}{l}\text { Grade of } \\
\text { Concrete }\end{array}$} & \multirow[t]{2}{*}{ W / C ratio } & \multirow[t]{2}{*}{ Slump in $\mathbf{m m}$} & \multirow[t]{2}{*}{ TJF Content (\%) } & \multicolumn{3}{|c|}{ Mix Proportions ) kg/m } \\
\hline & & & & Cement & Fine Aggregate & Coarse Aggregate \\
\hline \multirow{4}{*}{ M20 } & \multirow{4}{*}{0.49} & \multirow{4}{*}{$50-75$} & 0.00 & \multirow{4}{*}{396.75} & \multirow{4}{*}{747} & \multirow{4}{*}{1080} \\
\hline & & & 0.50 & & & \\
\hline & & & 0.60 & & & \\
\hline & & & 0.70 & & & \\
\hline \multirow{4}{*}{ M25 } & \multirow{4}{*}{0.46} & \multirow{4}{*}{$50-75$} & 0.00 & \multirow{4}{*}{409.78} & \multirow{4}{*}{725} & \multirow{4}{*}{1050} \\
\hline & & & 0.50 & & & \\
\hline & & & 0.60 & & & \\
\hline & & & 0.70 & & & \\
\hline
\end{tabular}

\section{Results and Discussion}

\section{Workability Test}

Slump test was conducted according to IS1199-1959 [25] to study the workability of concrete and to infer variation in the workability with the addition of fibers in concrete. The mix design was designed for the slump of $50-75 \mathrm{~mm}$ and the control mix was able to achieve the design slump. The addition of fibers reduces the workability when compared with the control mix but the values are well within the design slump limit. The slump results are shown in figure 3.

\section{Mechanical Properties}

The compressive strength properties of concrete were determined by testing concrete cubes after 28 days of curing in compression testing machine of $3000 \mathrm{kN}$ at constant loading rate 140 $\mathrm{kg} / \mathrm{mm}^{2} / \mathrm{min}$ and tested according to BIS516: 2004 [26].It was observed that concrete cubes containing treated jute fiber failed at higher compressive loads as compared to control specimen. The variation with in the various percentage of addition fibers tends that at 0.6 percentage addition fibers has higher strength than the other two percentage of addition of fibers. The decrease in the strength initiates from $0.7 \%$ this may be due to fiber agglomeration [27]. The percentage variation in the compressive strength of concrete are shown in figure 4 . Based on compressive strength and the slump value the optimum percentage of addition fiber was considered as $0.6 \%$ for the further study on flexural behaviour of reinforced concrete beams.

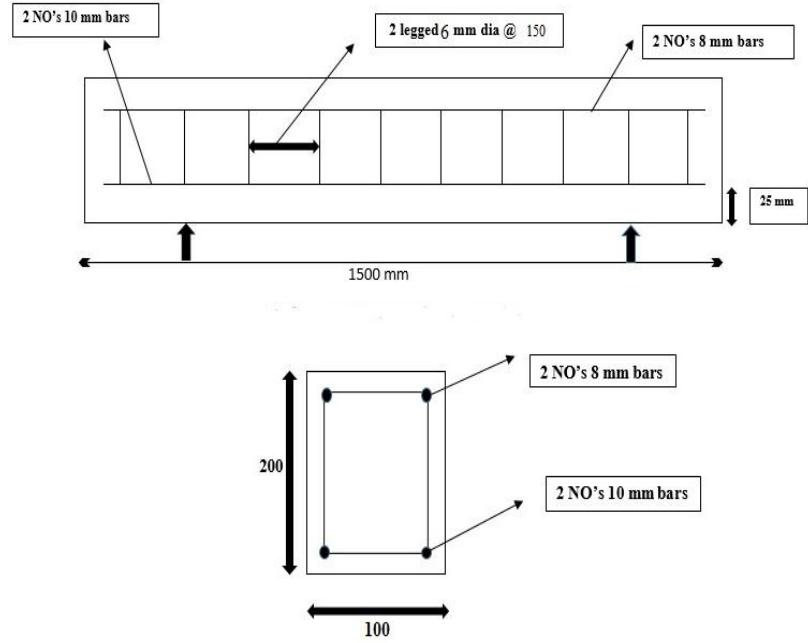

Fig. 1: Reinforcement details of beam 


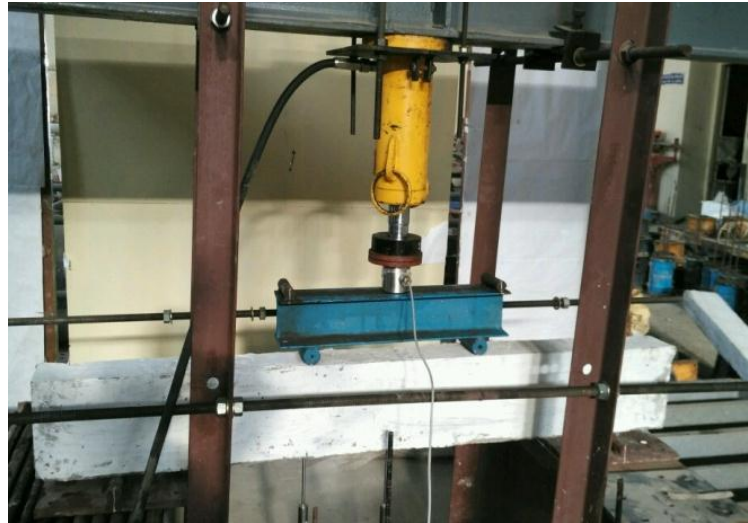

Fig. 2: Experimental setup for testing beams

\section{Flexural behaviour of RCC Beams}

The experimental study on reinforced concrete beam overwhelms to understand the behaviour and influence of addition of fibers, whilst, based on location of TF in the beam. Figure 5 provides details load versus deflection behaviour of M20 grade concrete and M25 grade concrete with and without TF, respectively.,

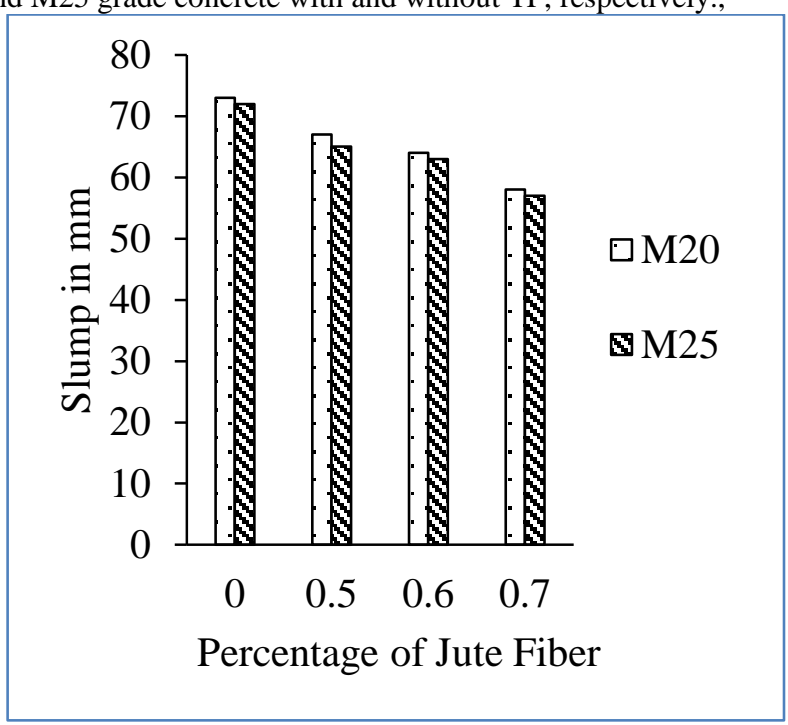

Fig. 3: Slump versus percentage of fiber content

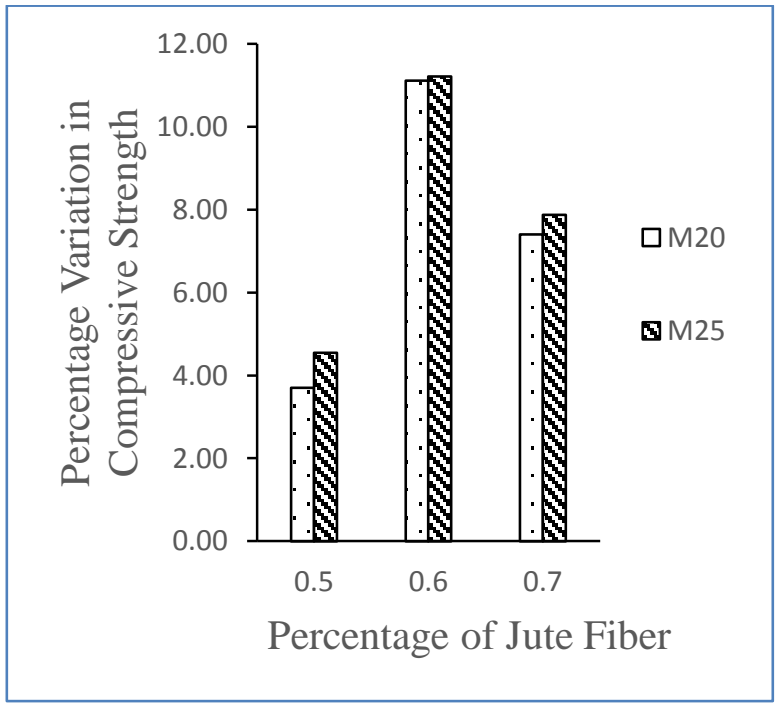

Fig. 4: Percentage variation in compressive strength and fiber content

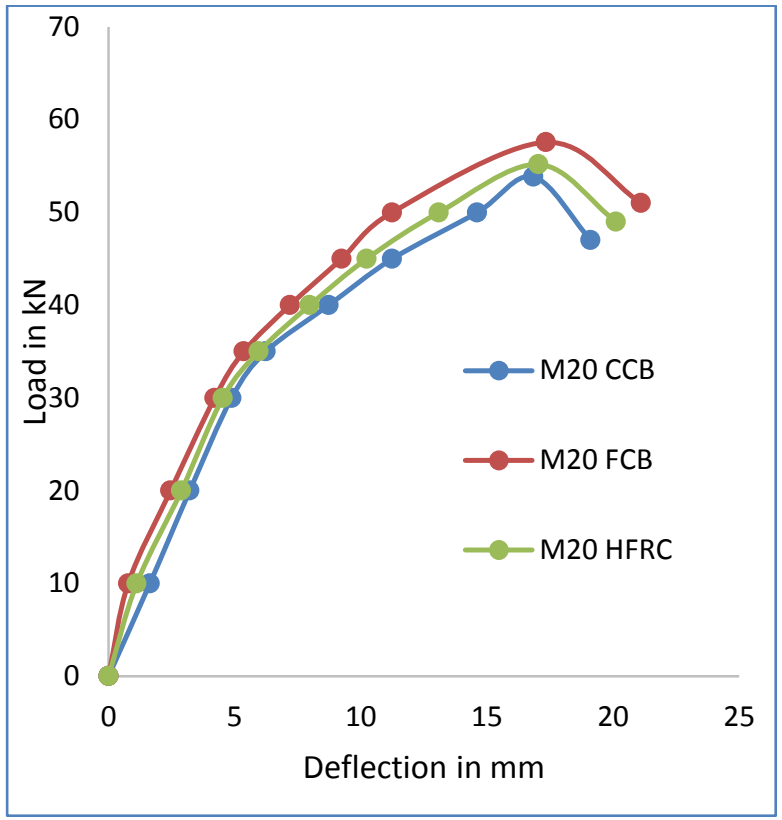

M20 Grade of Concrete

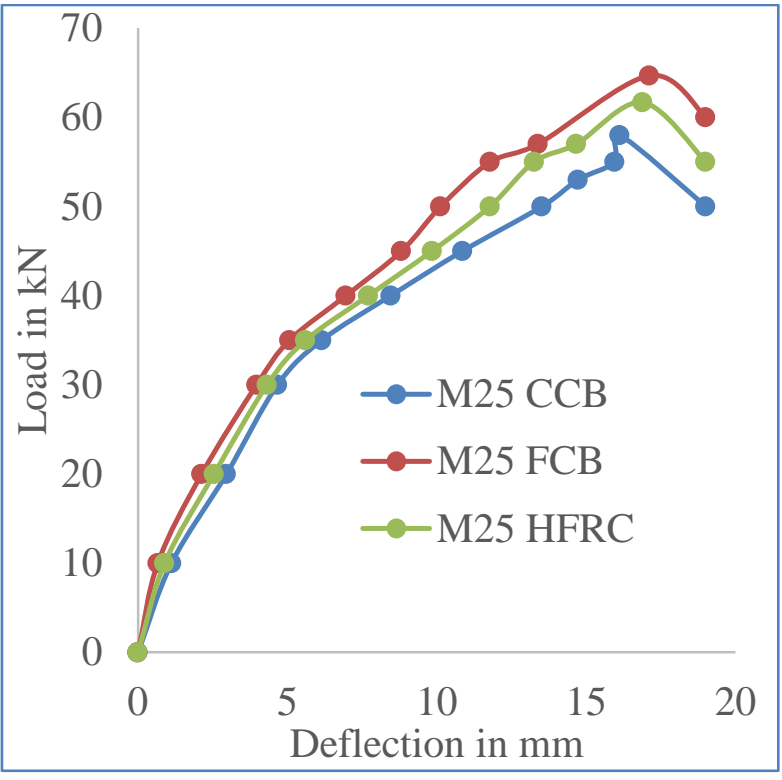

M25 Grade of Concrete

Fig. 5: Load versus deflection behaviour o[for with and without TF

The figure 5clearly depicts the presence of fiber increased the stiffness at the lower loads than the control beam, when comparing with the FRC and HFRC, the FRC beams had initial stiffness, ultimate capacity greater than the GFRC. Table 4 summaries the load and deflection at the various loading stages. The percentage increase in initial cracking load of M20 grade of concrete for FRC and HFRC were $12.92 \%$ and $6.00 \%$, respectively. The ultimate load carrying capacity of FRC and HFRC beams were $6.94 \%$ and $2.50 \%$, respectively. Similar observations were found for M25 grade concrete, the values were slightly varying but the variations were almost similar, the initial cracking load was increased by $11.23 \%$ and $7.29 \%$, respectively. The ultimate load carrying capacity of beams were increased by $7.20 \%$ and $2.21 \%$, respectively. The ductility ratio of the fiber added beam is enhanced than the control beam. The ductiltity ratios were $3.86,4.34,4.12$ for $\mathrm{CCB}$, FRC and HFRC, respectively. 
Table 4: Mix Proportions of Concrete

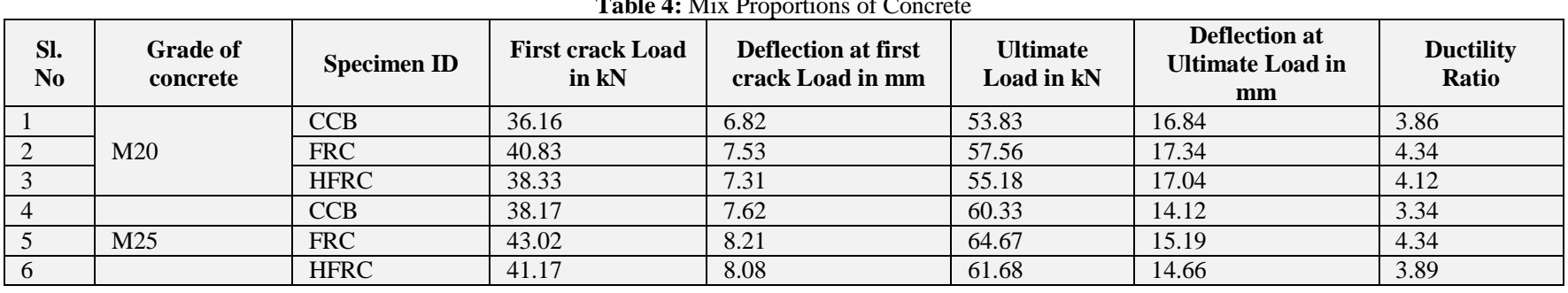

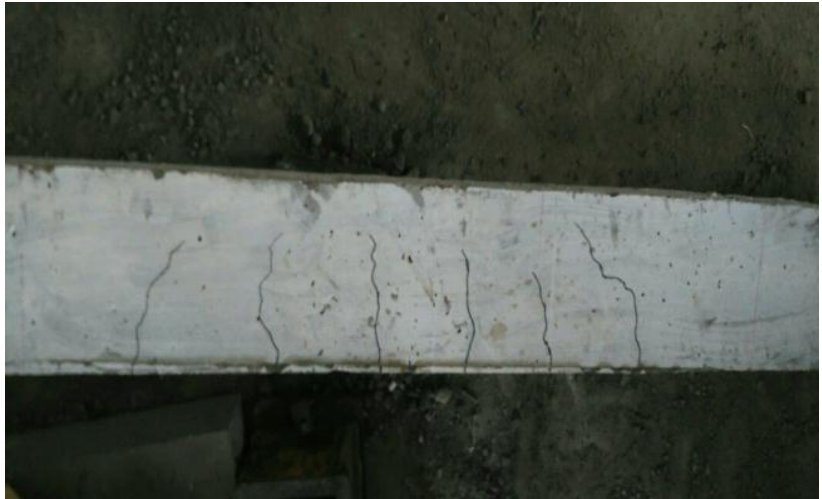

Fig. 6: Cracking pattern of beams

\section{Cracking and Mode of Failure}

Figure 6 shows the formation of crack, crack pattern and failure mode of the beams tested with and without fibers. The first crack was formed at the maximum bending moment zone and the load required was around $30 \%$ to $40 \%$ of the failure load. After initiation of first crack the load was further increased to study the formation of number of flexural cracks, crack patterns and crack width. The formation of crack patterns was found to be similar in all the types of beams but the number of cracks formed founds to vary between the FRC, CCB and HFRC beams. The FRC beams shows superior performance than other two types by forming less numbers of cracks and lesser crack widths. The study shows that presence of fiber on all the parts of the cross section enhances the behviour of beam under cracking and the presence of fiber delays the formation of cracks in flexure and lesser crack widths since the fiber added was acting as bridging element between the cracks.

\section{Conclusions}

In this study, treated jute fiber with alkali and polymer latex was used as addition as percentage to cement for $0.50 \%, 0.60 \%$ and $0.70 \%$. The optimum dosage of TJF were found experimentally based on the fresh properties, mechanical property of concrete for M20 and M25 grade of concrete.

- The slump shows a descending trend as the fiber id added in compared with Control specimen.

- The compressive strength of concrete is greater than the control specimen for all the percentage addition of fiber. But the values decreases after reaching a maximum for $0.6 \%$ addition of fiber, the decrease in compressive strength may attribute due to agglomeration of fiber beyond certain percentage.

- Optimum dosage of TJF content was $06 \%$ as an addition to cement content.

- The behviour of reinforced concrete beam under flexural was enhanced after addition of TJF.

- The presence of fiber in whole area increases the compressive strength and post cracking resistance by forming a bridge between cracks.

- The presence of TJF in whole area is more advantage than the control beam and HFRC in tension zone.

\section{References}

[1] Ramakrishna, G. and Sundararajan, T., 2005. Impact strength of a few natural fibre reinforced cement mortar slabs: a comparative study. Cement and concrete composites, 27(5), pp.547-553.

[2] Rabi, J.A., Santos, S.F., Tonoli, G.H. and Savastano Jr, H., 2009 Agricultural wastes as building materials: properties, performance and applications. Agriculture Issues and Policies Series, p.219.

[3] Chakraborty, S., Kundu, S.P., Roy, A., Adhikari, B. and Majumder, S.B., 2013. Polymer modified jute fibre as reinforcing agent controlling the physical and mechanical characteristics of cement mortar. Construction and Building Materials, 49, pp.214-222.

[4] Annual Report - Indian Council of Agricultural Research ICARNational Institute of Research on Jute \& Allied Fibre Technology. http://www.nirjaft.res.in/pdf/an1617.pdf

[5] De Andrade Silva, F., Toledo Filho, R.D., de Almeida Melo Filho, J. and Fairbairn, E.D.M.R., 2010. Physical and mechanical properties of durable sisal fiber-cement composites. Construction and building materials, 24(5), pp.777-785.

[6] Asasutjarit, C., Hirunlabh, J., Khedari, J., Charoenvai, S. Zeghmati, B. and Shin, U.C., 2007. Development of coconut coirbased lightweight cement board. Construction and Building Materials, 21(2), pp.277-288.

[7] Onésippe, C., Passe-Coutrin, N., Toro, F., Delvasto, S., Bilba, K. and Arsène, M.A., 2010. Sugar cane bagasse fibres reinforced cement composites: thermal considerations. Composites Part A: Applied Science and Manufacturing, 41(4), pp.549-556.

[8] Li, Z., Wang, X. and Wang, L., 2006. Properties of hemp fibre reinforced concrete composites. Composites part A: applied science and manufacturing, 37(3), pp.497-505.

[9] Swamy, R.N. and Mangat, P.S., 1975. The onset of cracking and ductility of steel fiber concrete. Cement and Concrete Research, 5(1), pp.37-53.

[10] de Andrade Silva, F., Mobasher, B. and Toledo Filho, R.D., 2009. Cracking mechanisms in durable sisal fiber reinforced cement composites. Cement and Concrete Composites, 31(10), pp.721-730.

[11] Savastano, H., Santos, S.F., Radonjic, M. and Soboyejo, W.O., 2009. Fracture and fatigue of natural fiber-reinforced cementitious composites. Cement and Concrete Composites, 31(4), pp.232-243.

[12] Aziz, M.A., Paramasivam, P. and Lee, S.L., 1981. Prospects for natural fibre reinforced concretes in construction. International Journal of Cement Composites and Lightweight Concrete, 3(2), pp.123-132.

[13] Elsaid, A., Dawood, M., Seracino, R. and Bobko, C., 2011. Mechanical properties of kenaf fiber reinforced concrete. Construction and Building Materials, 25(4), pp.19912001.

[14] Li, X., Tabil, L.G. and Panigrahi, S., 2007. Chemical treatments of natural fiber for use in natural fiber-reinforced composites: a review. Journal of Polymers and the Environment, 15(1), pp.25-33.

[15] Tonoli, G.H.D., Rodrigues Filho, U.P., Savastano, H., Bras, J., Belgacem, M.N. and Lahr, F.R., 2009. Cellulose modified fibres in cement based composites. Composites Part A: Applied Science and Manufacturing, 40(12), pp.2046-2053.

[16] Olorunnisola, A.O., 2009. Effects of husk particle size and calcium chloride on strength and sorption properties of coconut huskcement composites. Industrial Crops and Products, 29(2), pp.495501

[17] Ismail, M.R., Youssef, H.A., Ali, M.A., Zahran, A.H. and Afifi, M.S., 2008. Utilization of emulsion polymer for preparing bagasse fibers polymer-cement composites. Journal of applied polymer science, 107(3), pp.1900-1910.

[18] Jarabo, R., Fuente, E., Monte, M.C., Savastano, H., Mutjé, P. and Negro, C., 2012. Use of cellulose fibers from hemp core in fibercement production. Effect on flocculation, retention, drainage and product properties. Industrial Crops and Products, 39, pp.89-96. 
[19] Kundu, S.P., Chakraborty, S., Roy, A., Adhikari, B. and Majumder, S.B., 2012. Chemically modified jute fibre reinforced non-pressure (NP) concrete pipes with improved mechanical properties. Construction and Building Materials, 37, pp.841-850

[20] Herrera-Franco, P.J. and Valadez-Gonzalez, A., 2004. Mechanical properties of continuous natural fibre-reinforced polymer composites. Composites Part A: applied science and manufacturing, 35(3), pp.339-345.

[21] Roy, A., Chakraborty, S., Kundu, S.P., Basak, R.K., Majumder, S.B. and Adhikari, B., 2012. Improvement in mechanical properties of jute fibres through mild alkali treatment as demonstrated by utilisation of the Weibull distribution model. Bioresource technology, 107, pp.222-228.

[22] Chakraborty, S., Kundu, S.P., Roy, A., Adhikari, B. and Majumder, S.B., 2013. Polymer modified jute fibre as reinforcing agent controlling the physical and mechanical characteristics of cement mortar. Construction and Building Materials, 49, pp.214-222.

[23] Bureau of Indian Standards (BIS). Code of practice for 43 Grade Ordinary Portland Cement: New Delhi, BIS; 1989. Standard No. IS-8112: 2005

[24] Bureau of Indian Standards (BIS). Code of Practice - Specification for Coarse and Fine Aggregate from Natural Sources for Concrete: New Delhi: BIS; 1970. Standard No IS 383: 2002.

[25] Bureau of Indian Standards (BIS). Code of Practice - Specification for Sampling and analysis of concrete: New Delhi: BIS; 1959. Standard No IS 1199-1959.

[26] Bureau of Indian Standards (BIS). Code of Practice - Methods of test for strength of concrete: New Delhi, BIS; 1959. Standard No IS 516: 1997.

[27] Zakaria, M., Ahmed, M., Hoque, M.M. and Islam, S., 2017. Scope of using jute fiber for the reinforcement of concrete material. Textiles and Clothing Sustainability, 2(1), p.11. 